\title{
Craniometadiaphyseal dysplasia, wormian bone type
}

INSERM

\section{Source}

INSERM. (1999). Orphanet: an online rare disease and orphan drug data base.

Craniometadiaphyseal dysplasia, wormian bone type. ORPHA:85184

Craniometadiaphyseal dysplasia, wormian bone type is an extremely rare craniotubular bone dysplasia syndrome described in fewer than 10 patients to date. Clinical

manifestations include macrocephaly, frontal bossing, malar hypoplasia, prominent

mandible and dental hypoplasia. Other skeletal anomalies include abnormal bone

modeling in tubular bones, multiple wormian bones and deformities of chest, pelvis and elbows. An increased risk of fractures is noted. 